\title{
BMJ Open Pharmaceutical use and costs in patients with coronary artery disease, using Australian observational data
}

\author{
Victoria McCreanor (D) ,1,2 William A Parsonage (D) ,,3 David C Whiteman, ${ }^{4,5}$ \\ Catherine Olsen (D) , ${ }^{4,5}$ Adrian G Barnett (D) , ${ }^{1}$ Nicholas Graves (D) ${ }^{1}$
}

To cite: McCreanor $V$, Parsonage WA, Whiteman DC, et al. Pharmaceutical use and costs in patients with coronary artery disease, using Australian observational data. BMJ Open 2019;9:e029360. doi:10.1136/ bmjopen-2019-029360

- Prepublication history and additional material for this paper are available online. To view these files, please visit the journal online (http://dx.doi. org/10.1136/bmjopen-2019029360).

Received 23 January 2019

Revised 24 May 2019

Accepted 19 August 2019

Check for updates

(C) Author(s) (or their employer(s)) 2019. Re-use permitted under CC BY-NC. No commercial re-use. See rights and permissions. Published by BMJ.

${ }^{1}$ Australian Centre for Health Services Innovation (AusHSI), Institute of Health and Biomedical Innovation, Queensland University of Technology, Brisbane, Queensland, Australia ${ }^{2}$ Capital Markets CRC Ltd, Sydney, New South Wales, Australia

${ }^{3}$ Cardiology, Royal Brisbane and Women's Hospital, Herston, Queensland, Australia

${ }^{4}$ QIMR Berghofer Medical

Research Institute, Brisbane, Queensland, Australia

${ }^{5}$ Faculty of Medicine, University of Queensland, Brisbane, Queensland, Australia

Correspondence to Victoria McCreanor; victoria.mccreanor@qut.edu.au

\section{ABSTRACT}

Objectives We aimed to estimate the annual pharmaceutical costs for patients with stable coronary artery disease, using Australian administrative data, comparing patients who had undergone interventional treatment with those had not. We also aimed to compare the duration of dual antiplatelet therapy (DAPT) prescription in the real-world, with recommended guidelines.

Design An observational study using administrative data. Participants We used data from the QSkin study, a population-based prospective study assessing skin cancer risk. Participants were invited from the Queensland population, not based on perceived skin cancer risk, and had consented to future use of their data for approved research projects.

Main outcome measures We calculated 12-month costs of pharmaceutical therapy for coronary artery disease for patients in each of three clinically relevant groups: medical therapy only, following coronary stent implantation and following coronary artery bypass graft surgery. We measured the duration of DAPT following stent implantation and total duration of DAPT, where it was prescribed, in the medical therapy only group.

Results Estimated mean annual pharmaceutical costs were highest in the stent group at AUD\$1920, compared with AUD $\$ 1481$ in the medical therapy group, and AUD\$881 in the coronary artery bypass group. There were similar rates of prescriptions of symptom relief drugs following stent insertion, compared with the medical therapy only group. The median duration of DAPT in the stent group was 16, and 31 months in the medical therapy group.

Conclusions Our results suggest that despite the common expectation that the burden of medical therapy is reduced following coronary stent insertion for stable coronary artery disease, this does not occur in practice. Many patients also appear to continue DAPT longer than guidelines recommend, which may put them at unnecessarily elevated risk of bleeding events.

\section{INTRODUCTION}

In a time of increased pressure on health budgets the assessment of all costs associated with different treatment options is essential. There is current debate about the incremental benefits of percutaneous

\section{Strengths and limitations of this study}

The strength of this research is that it estimates the real-world costs and duration of dual antiplatelet therapy in Australia, outside the controlled environment of a clinical trial, and is therefore highly relevant for health system policy-makers.

- A limitation of administrative data is that they do not contain information about clinical indications or reasons for starting or ending different prescriptions.

- For the medical therapy group, we relied on selfreporting of coronary artery disease as a condition for which they see a specialist. We therefore may have missed some patients in that group who are managed solely in primary care.

coronary intervention as an addition to medical therapy only, for patients with stable coronary artery disease. ${ }^{1}$ Percutaneous coronary interventions incur costs in addition to the primary procedure and economic evaluations should include these costs. In particular, the costs associated with guidelinerecommended prescription drugs should be included. Compared with medical therapy alone, the other two main treatments for stable coronary artery disease, percutaneous coronary intervention (PCI) and coronary artery bypass graft (CABG) surgery, should reduce the need for antianginal therapies, but following percutaneous coronary intervention with stent insertion, dual antiplatelet therapy (DAPT) is recommended. ${ }^{1-3}$

Changes to clinical guidelines and clinical practice may also influence costs and therefore the cost-effectiveness of different treatments. The clinical guidelines for the duration of DAPT following percutaneous coronary intervention with stent insertion have changed over time, and there is now evidence that a shorter duration of DAPT, of between 6 and 12 months, may be noninferior to longer treatment periods, of 12 months or more, in many patients. ${ }^{2-6} \mathrm{~A}$ 
shorter duration of DAPT should reduce costs and may improve the cost-effectiveness of percutaneous coronary intervention.

We do not have good information about the pharmaceutical costs for medical management of Australian patients with coronary artery disease, or about changes to these costs following invasive therapy with percutaneous coronary intervention and CABG surgery. It is also not known how well guidelines are followed and how long the average duration of DAPT is in Australian patients.

To address this knowledge gap, we have investigated the average annual pharmaceutical costs for three groups of patients with coronary artery disease in Australia: following coronary stent insertion, following CABG surgery and those receiving medical therapy only. We also assessed the duration of DAPT prescribed in patients following coronary stent insertion and in a group of medically managed patients.

\section{METHODS}

We assessed the current prescribing practices for coronary artery disease in Australia, using linked administrative data from the Medicare Benefits Schedule (MBS) and the Pharmaceutical Benefits Scheme (PBS). Medicare is Australia's universal healthcare system which subsidises all Australian citizens and permanent residents. The MBS lists medical services subsidised by the Australian government and the PBS lists all subsidised pharmaceuticals. Medicare subsidises virtually all medical services outside of the public hospital system.

These data were originally collected and linked for the QSkin study ${ }^{7}$ a population-based prospective study assessing skin cancer risk; at baseline participants provided consent for future use of their data for approved research projects. Participants were approached from the Queensland electoral roll, not based on perceived skin cancer risk, and therefore data are useful for population level studies of other disease outcomes. Of 193344 persons aged 40-69 years selected at random from the Queensland Electoral Roll (voter registration is compulsory by law in Queensland, Australia, for all persons over the age of 18 years) and invited to take part in the study, $\sim 40000$ people agreed to participate. Recruitment took place between November 2010 and December 2011. All participants completed a baseline survey which included questions about demographics and general medical history, including a question regarding aspirin use in the preceding year. This makes them an ideal cohort for assessing heart disease. MBS and PBS data for the QSkin cohort were available from date of consent through to June 2014.

\section{Patient and public involvement}

We used deidentified data from the QSkin study, therefore there was no public or patient involvement in this study.

\section{Identifying relevant drugs}

PBS listed pharmaceuticals used for the treatment of coronary artery disease were identified by an experienced
Table 1 Pharmaceuticals used in medical treatment of stable coronary artery disease

\begin{tabular}{ll}
\hline Function & Drug category \\
\hline $\begin{array}{l}\text { Reduce risk of blood } \\
\text { clots }\end{array}$ & $\begin{array}{l}\text { Antiplatelet (aspirin, clopidogrel, } \\
\text { prasugrel, ticagrelor) }\end{array}$ \\
$\begin{array}{l}\text { Slow disease } \\
\text { progression }\end{array}$ & Lipid modifiers (fibrates, statins) \\
Symptom relief & $\begin{array}{l}\text { Beta blockers } \\
\text { Calcium channel blockers } \\
\text { Nitrates } \\
\text { Renin angiotensin system } \\
\text { antagonists } \\
\text { Others (eg, other vasodilators and } \\
\text { ivabradine) }\end{array}$ \\
\hline
\end{tabular}

cardiologist. Pharmaceutical therapy for coronary artery disease combines drugs designed to treat symptoms, slow disease progression and reduce the risk of acute cardiovascular events such as myocardial infarction. This combination commonly includes antiplatelet medication, lipid-lowering drugs and antianginal drugs for symptom relief. The pharmaceuticals identified are broadly categorised as shown in table 1 .

The Australian PBS uses its own coding system alongside the international Anatomical Therapeutic Chemical (ATC) Classification System, defined by the WHO Collaborating Centre for Drug Statistics Methodology at the Norwegian Institute of Public Health. ${ }^{89}$ We used the ATC codes to generate a list of relevant PBS codes. The PBS 'drug' list, which includes PBS and corresponding ATC codes is available to download from the PBS website. ${ }^{10} \mathrm{~A}$ full list of the PBS codes used in this research is in the online supplementary materials.

\section{Identifying relevant patients}

We compared PBS costs for patients with coronary heart disease treated with the three recognised means of treatment:

1. Medical therapy group: medical therapy without interventional procedures for coronary artery disease.

2. Stent group: post percutaneous coronary intervention with stent insertion.

3. CABG group: post CABG surgery.

Patients with coronary artery disease were identified through self-reporting of heart disease in response to a question in the QSkin survey which asked participants if they had 'a serious medical condition requiring treatment by a specialist'. This free text question was coded using the International Classification of Diseases, Tenth Edition. All coding was performed by a single, medically qualified reviewer who used ICD-10-AM coding scheme. Difficult or challenging reports were discussed with a medically qualified supervisor. The codes were then reviewed in batches by the supervisor. Participants who underwent stenting and CABG procedures were identified using MBS item codes. (A list of MBS codes used to identify these patients is in the online supplementary 
materials.) To allow for a full year's data following the procedure, we limited our searches to patients who had a procedure on or before 30 June 2013.

We excluded patients without private health insurance from the medical therapy group, because MBS data are recorded only for privately provided procedures, and we wanted to reduce the risk of including patients who had a procedure in a public setting, which would not be recorded in their MBS data. It was not necessary to do this for the other two groups because the existence of a relevant MBS item was enough to include them in either the stent or CABG group, and access to pharmaceuticals listed on the PBS is not affected by a person's private health insurance status. Private health insurance coverage in Australia is high and therefore we felt that the insured population should be generalisable to the greater population. At 30 June 2012, 46.6\% of Australians held private health insurance, ${ }^{11}$ with the highest levels of coverage in 2004-2005 reported in the 45-54 and 55-64 years age groups. ${ }^{12}$

In summary, the three groups were categorised in the following way:

1. A medical therapy group, of patients treated for coronary artery disease, who satisfied all of the following:

a. reported a history of coronary artery disease,

b. reported they had private health insurance,

c. had no interventional procedure recorded in the MBS data,

d. were taking at least two different types of drugs commonly used to treat coronary disease and

e. earliest relevant prescription on or before 30 June 2013.

2. A stent group, with a stent procedure recorded in the MBS data.

a. Most recent stent procedure on or before 30 June 2013.

3. A $C A B G$ group, with a $\mathrm{CABG}$ procedure recorded in the MBS data.

a. CABG procedure on or before 30 June 2013.

We also compared relevant characteristics across the three groups; including smoking and diabetes, which both increase the risk of acute coronary events and death in these patients, noting that these relied on self-reporting.

\section{Calculating annual costs}

There is variability in the dosages and pack sizes both within and across different pharmaceuticals prescribed in Australia. This creates variation in the timing for patients filling prescriptions. Repeat prescriptions may also require follow-up appointments with doctors and hence there may be delays in filling prescriptions for ongoing medical treatment. To account for this, we assessed 12-month periods for each patient.

For patients in the medical therapy group, we extracted PBS data for relevant drugs for one full year, following the first supply date for each patient. To avoid incomplete prescription histories, we restricted our search to only participants who had at least one full year's PBS data, by limiting the search to those with a first supply date on or before 30 June 2013 . We used these data to calculate the average annual costs per patient.

To calculate the costs of pharmaceutical therapy following coronary stent insertion or CABG surgery, we took PBS prescription data for relevant drugs in the 12 months following a procedure recorded in MBS data. All costs were inflated to 2017 prices using the pharmaceuticals index available from the Australian Bureau of Statistics. ${ }^{13}$ We present the mean cost per patient group together with a $95 \%$ CI for the mean.

\section{Duration of DAPT}

To assess how long patients received DAPT, we calculated the time period from each patient's last recorded stent, as recorded in the MBS data, and the last recorded date of supply of antiplatelet drug, other than aspirin, or combination formulation in the corresponding PBS data. The MBS data do not report the type of stent used, so we were unable to differentiate by stent type.

We searched the data for patients who had had a stent prior to 2013, to allow for at least 18 months after the date of the stent procedure. We then calculated the time period from their last stent to their last supply of antiplatelet drug, other than aspirin. Aspirin is part of DAPT, but as it is available at low cost without prescription, it may not be recorded in the PBS data for many patients. To avoid including patients who were prescribed DAPT for reasons other than following a percutaneous coronary intervention, we also excluded patients who had nonaspirin antiplatelet therapy prescribed more than 15 days prior to their most recent stent procedure.

We also assessed the prescribing of DAPT in patients in the medical therapy group. In that group, we used data from patients who had a first date of supply of a relevant drug prior to 2013, to allow for at least 18 months. We classified patients as receiving DAPT if they had a relevant non-aspirin antiplatelet prescription and indicated in the QSkin baseline survey that they took aspirin more than once per week 'during the past year'. This was done to avoid including patients who were prescribed a non-aspirin antiplatelet drug because of intolerance to aspirin. We were not able to apply the same criterion to the post-stent group, because the MBS data related to the time period after the QSkin survey was conducted, and so answers to the survey questions may not relate to the period following the stent procedure. However, expert clinical opinion is that there are strong grounds to assume that most patients would also be taking aspirin following coronary stent insertion, as this forms the second part of DAPT.

In summary, the two DAPT groups were categorised in the following way:

1. The stent group.

a. With a stent procedure on or before 31 December 2012.

b. Without a non-aspirin antiplatelet in the 15 days prior to the stent procedure. 


\begin{tabular}{llcc|}
\hline \multirow{4}{*}{ Table 2} & \multicolumn{4}{l}{ Characteristics of patients in each group } \\
& Medical therapy & Stent & CABG \\
\hline Number & 609 & 92 & 39 \\
Females (\%) & 16 & 17 & 8 \\
Mean age (SD) & $62(6)$ & $62(5)$ & $63(5)$ \\
Current smoker (\%) & 5 & 9 & 5 \\
Past smoker (\%) & 48 & 50 & 44 \\
Diabetes $^{*}(\%)$ & 7 & 9 & 8 \\
\hline
\end{tabular}

*Patients who had reported diabetes as serious condition for which they had seen a specialist, in the baseline QSkin survey. CABG, coronary artery bypass graft.

c. Prescription of non-aspirin antiplatelet therapy.

2. The medical therapy group.

a. Prescription of non-aspirin antiplatelet therapy.

b. Indicated that they took aspirin more than once per week in the previous year.

c. First prescription on or before 31 December 2012.

\section{RESULTS}

\section{Costs of medical therapy}

The relevant characteristics of patients are similar in the three groups we examined, with the exception of the percentage of females in the CABG group, which is lower than the other two groups (table 2).

The costs of pharmaceuticals for treating coronary artery disease in the three groups are compared in table 3. The average annual pharmaceutical costs following coronary stent insertion were higher than for both the medical therapy and CABG surgery groups. The CABG group had the lowest annual pharmaceutical costs compared with the other two groups. The difference in total annual costs across the three groups is driven largely by differences in antiplatelet therapy costs.

The percentage of patients in each group with prescriptions from each of the drug categories is in table 3. It is important to note that aspirin is commonly purchased without prescription in Australia and therefore very few of the antiplatelet prescriptions in our data relate to aspirin. Again, the greatest differences in prescribing patterns between the three groups relate to antiplatelet drugs, with $97 \%$ of the stent group having at least one prescription compared with only $44 \%$ in the medical therapy group and $42 \%$ in the coronary artery bypass groups. There are smaller differences in prescribing patterns of symptom relief drugs. These do not appear to be substantially different following either a stent or CABG surgery compared with the medical therapy group. However, patients following stent insertion had the highest rates of use of the three main classes of drugs used for relief of angina (beta blockers, nitrates and calcium channel blockers).

The distributions of pharmaceuticals' costs across the three groups; medical therapy, post-stent and post-CABG are in figure 1 . The distributions apply to the range of annual costs for each type of drug, assessed only across patients prescribed each drug type, as opposed to the average across all patients in the group.

\section{Duration of DAPT}

A total of 49 patients fit the search criteria to assess the duration of DAPT following coronary stent implantation and 141 patients fit the criteria for the medical therapy and DAPT group (table 4).

The median time from last stent to last antiplatelet supply was 16 months with a maximum of 40 months (table 5). The median total DAPT time in the medical therapy group was 31 also with a maximum of 40 months

Table 3 Comparison of estimated average annual pharmaceutical costs (AUD\$) per patient in three groups of patients with coronary artery disease

\begin{tabular}{|c|c|c|c|c|c|c|}
\hline \multirow[b]{2}{*}{ Drug category } & \multicolumn{2}{|c|}{ Medical therapy $(n=609)$} & \multicolumn{2}{|c|}{ Stent $(n=92)$} & \multicolumn{2}{|c|}{ CABG (n=39) } \\
\hline & $\%$ & Mean $(95 \% \mathrm{Cl})$ & $\%$ & Mean $(95 \% \mathrm{Cl})$ & $\%$ & Mean $(95 \% \mathrm{Cl})$ \\
\hline Antiplatelet* & 44 & 266 (234 to 298$)$ & 98 & 849 (764 to 933$)$ & 41 & $60(6$ to 115$)$ \\
\hline Symptom relief (total) & 66 & 239 (213 to 264$)$ & 71 & 280 (209 to 352) & 67 & 218 (126 to 310$)$ \\
\hline Beta blocker & 36 & 62 (47 to 77$)$ & 43 & 69 (30 to 107$)$ & 26 & 63 (11 to 116$)$ \\
\hline Nitrate & 19 & 18 (13 to 22$)$ & 34 & 26 (15 to 38$)$ & 13 & $4(0$ to 8$)$ \\
\hline Renin angiotensin agent & 53 & 125 (112 to 139$)$ & 57 & 138 (103 to 174$)$ & 54 & 132 (79 to 186$)$ \\
\hline Other & 3 & 6 (3 to 10$)$ & 5 & $7(0$ to 15$)$ & 0 & $0(0)$ \\
\hline Total & & 1481 (1416 to 1546$)$ & & 1920 (1752 to 2089$)$ & & 881 (739 to 1023$)$ \\
\hline
\end{tabular}

$\%$ means percentage in the group with at least one prescription from that drug category.

*Seventy per cent of the medical therapy group, 34\% of the stent group and 38\% of the CABG group indicated they took aspirin more than once per week in the last year.

CABG, coronary artery bypass graft. 
Treatment

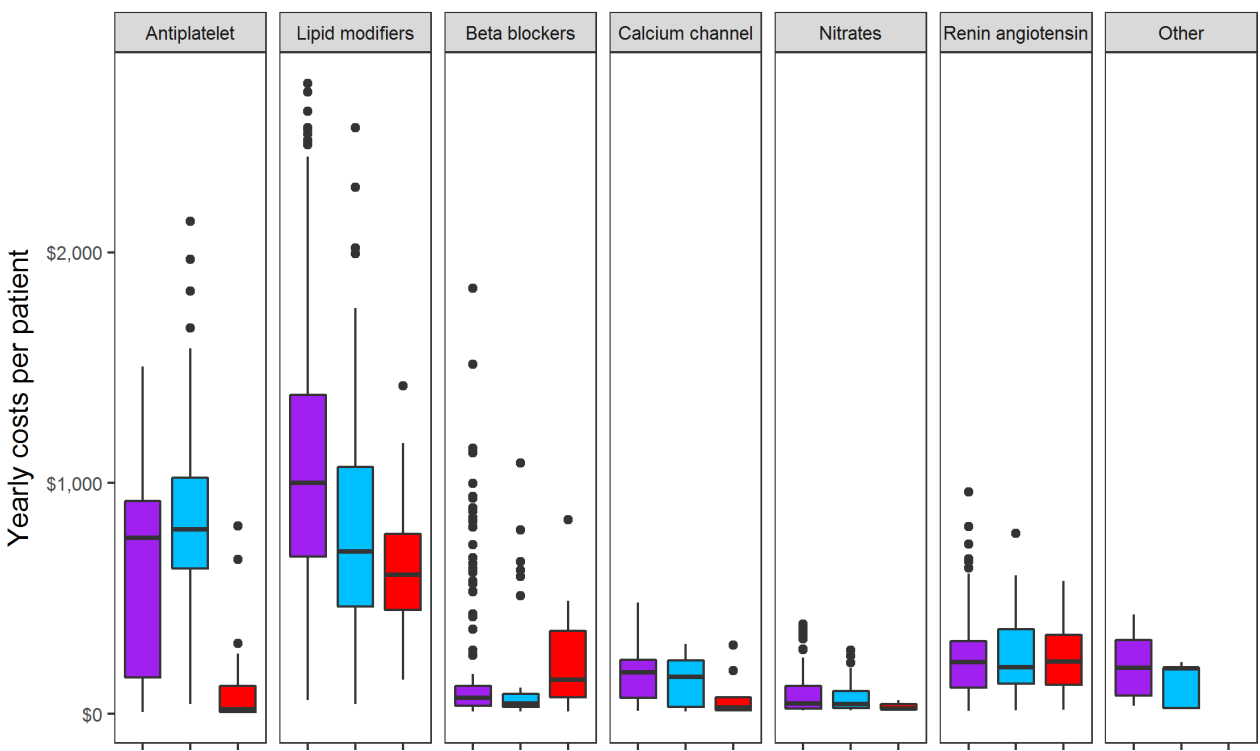

Figure 1 Box plots comparing pharmaceutical costs across the three groups: medical therapy, stent and CABG. Distributions apply only to patients prescribed each particular drug type, rather than across all patients in each group. ${ }^{*}$ Other is missing from the CABG group because they were not prescribed to any patients in that group. CABG, coronary artery bypass graft.

(table 5). The minimum in both groups was one prescription, indicating a duration of 1 month (most packs contain 28 tablets-see online supplementary materials).

The distribution for the duration of DAPT for individual patients is shown in figure 2 . In the stent group, we found that more than $60 \%$ of patients received DAPT for longer than 12 months, $45 \%$ over 18 months and $20 \%$ for longer than 24 months. In the medical therapy group, we found even greater percentages of patients were prescribed DAPT for over 12 months, with only $21 \%$ of patients receiving the therapy for up to 12 months. In that group, $79 \%$ received DAPT for over 12 months, $70 \%$ for longer than 18 months and $61 \%$ for over 24 months.

\section{DISCUSSION}

\section{Total costs}

A common argument for carrying out percutaneous coronary intervention in patients with stable coronary artery disease is that the procedure reduces the burden of medical therapy, both in terms of the number of pills

\begin{tabular}{lcc}
\hline $\begin{array}{l}\text { Table } 4 \\
\text { antiplatelet therapy in medical therapy and post-stent } \\
\text { groups }\end{array}$ & Medical therapy & Stent \\
\hline \multicolumn{4}{l}{ Number } & 141 & 49 \\
\hline Females (\%) & 16 & 18 \\
Mean age, years (SD) & $61(7)$ & $62(5)$ \\
Current smoker (\%) & 7 & 4 \\
Past smoker (\%) & 50 & 49 \\
Diabetes (\%) & 10 & 10 \\
\hline
\end{tabular}

patients are required to take and also on costs. This rationale pertains particularly to reducing the need for symptom relief medications following percutaneous coronary intervention. Our research, however, suggests that the reverse may be true. Patients in the stent group had higher pharmaceutical costs than both the medical therapy and CABG groups. While we have not explored the statistical significance of differences between groups, we note that the $95 \%$ CIs for total costs do not overlap, and the size of the cost difference is likely to have public health significance given the large number of patients receiving stents. Differences are largely driven by the additional costs for DAPT; however, we saw minimal variation in the prescription of other drugs. This suggests that following percutaneous coronary intervention, the burden of medical therapy remains high when compared with patients treated medically or with coronary artery bypass surgery. We are unable to tell whether this is due to the complexity of the underlying disease, ongoing symptoms, or that their prescriptions are not actively reduced

Table 5 Duration of dual antiplatelet therapy following stent implantation and in medical therapy group

\begin{tabular}{lcc}
\hline & Medical therapy & Stent \\
\hline No of patients & 141 & 49 \\
$\begin{array}{l}\text { Median duration of DAPT } \\
\text { (months) }\end{array}$ & 31 & 16 \\
$\begin{array}{l}\text { Maximum duration of DAPT } \\
\text { (months) }\end{array}$ & 40 & 40 \\
$\begin{array}{l}\text { Minimum duration of DAPT } \\
\text { (months) }\end{array}$ & 1 & 1 \\
\hline
\end{tabular}

DAPT, dual antiplatelet therapy. 


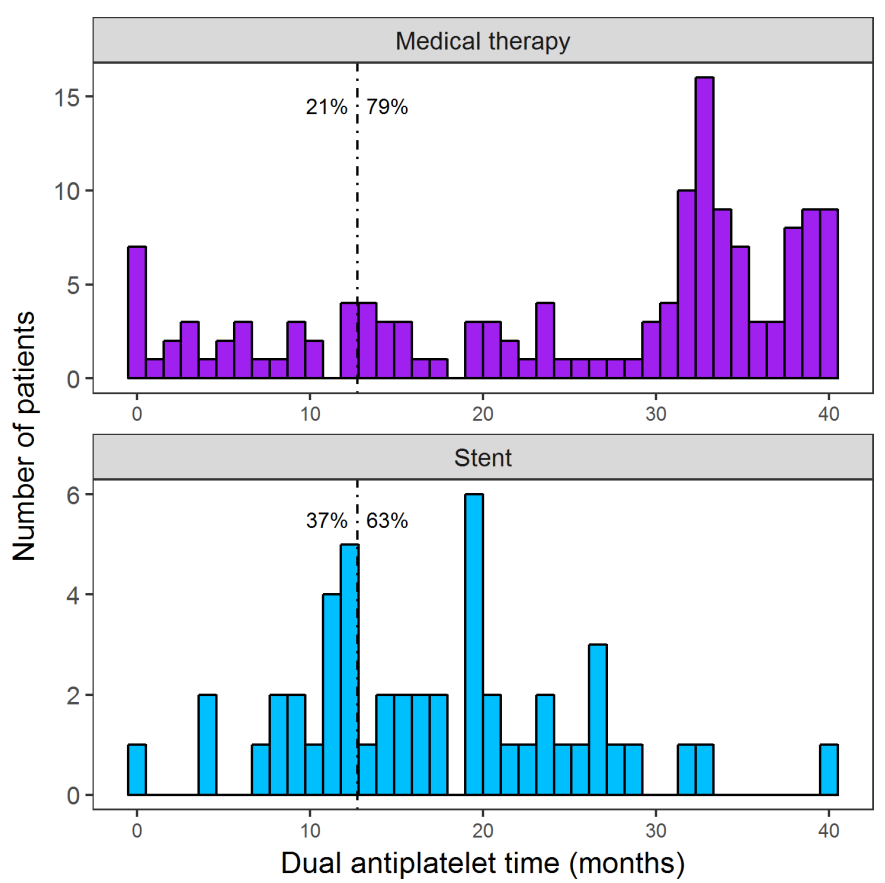

Figure 2 Frequency of duration of dual antiplatelet therapy following medical therapy or coronary stent implantation *Vertical line at 13 months, to show durations up to and over 12 months.

following the procedure. The average costs of symptom relief were similar across all three groups, but slightly lower following CABG, mostly due to lower calcium channel blocker and nitrate costs.

\section{Duration of DAPT}

Our results show substantial variation in the duration that DAPT was continued, and that it was often continued for longer than clinical guidelines prevailing at the time of the study. ${ }^{14}$ DAPT was continued for over 12 months in more than $60 \%$ of patients following a coronary stent procedure and almost $80 \%$ of the medical therapy group. Our data only ran until June 2014 and therefore it is possible that some patients continue to receive DAPT for even longer.

DAPT is primarily indicated to prevent stent thromboses in patients following stent insertion, and to prevent recurrent ischaemic events in patients following acute coronary syndromes. Both stent thromboses and ischaemic events can be catastrophic for patients and therefore longer durations of DAPT may be indicated and prescribed for patients with a high risk of these complications. However, the benefits of DAPT are invariably offset by an increase in the risk of bleeding, compared with aspirin alone, which can also have severe consequences, and there is evidence that these risks outweigh the risks of thrombotic events. ${ }^{16}$ Therefore, balancing these risks for individual patients is an important part of clinical decision-making.

The evidence and recommendations for DAPT have evolved substantially over the last 15 years, including the period of the data we analysed. Significant uncertainty followed for a period after 2006 when concern was raised regarding the possibility of an increased risk of very late (longer than 12 months after the procedure) stent thrombosis when DAPT was stopped after implantation of drug-eluting stents. However, by the time data were collected for this study, the European society guidelines for duration of DAPT were 6-12 months in patients following percutaneous coronary intervention with stable coronary disease ${ }^{17}$ and 12 months following acute coronary syndrome, regardless of whether percutaneous coronary intervention was the initial management strategy or not. ${ }^{18}$ By 2016, the Australian guidelines also reflected this approach in recommending DAPT for up to 12 months in patients following acute coronary syndromes regardless of whether coronary revascularisation was performed, and continuation beyond 12 months was only recommended in individuals at a high risk of recurrent ischaemic events. $^{19}$

There is an increased awareness of the risk of significant bleeding events in patients receiving DAPT and that the prognostic implications of these events are similar to those of recurrent ischaemic events. The American College of Cardiology and the European Society of Cardiology have recently released focused updates on duration of DAPT in the relevant clinical settings. ${ }^{23}$ A number of tools are available to assist clinicians in stratifying the competing risks of bleeding and recurrent ischaemia and use of these tools has been recommended. ${ }^{2319}$

\section{Limitations}

Our data and analyses are not without limitations. For the medical therapy group, we relied on QSkin survey participants having self-reported their coronary disease, meaning we may have missed some patients who did not consider their condition severe, or who were being managed by their primary care physician rather than by a specialist.

We acknowledge that some of our sample relates to only to patients with private health insurance. However, we note in the methods that private health insurance coverage is high in Australia and we therefore feel that excluding some uninsured patients should not bias our results substantially or affect their generalisability.

In addition, we note that there are fewer females in our study groups, compared with the greater population of patients with coronary artery disease in Australia. Figures from the Australian Institute for Health and Welfare indicate that $25 \%$ of PCIs and $18 \%$ of CABGs were carried out in females. ${ }^{20}$ In our data, there were $17 \%$ and $8 \%$ females, respectively. It is possible that this may have biassed our results; however while our figures are slightly different from national figures, we would expect the treatment for males and females to be very similar.

Because our data are administrative only, we could not evaluate the severity and complexity of coronary artery disease in individual patients, nor were we able to assess comorbidities beyond those reported by patients in the survey. This may have influenced the need for antianginal 
therapy in the patient groups. It is possible that the medical therapy group had less severe disease than the other groups, explaining why symptom relief was still frequently required following intervention in the stent and CABG groups. However, the medical therapy group only included patients who had self-reported coronary disease as a serious condition for which they had seen a specialist. Regardless, the types of pharmaceuticals prescribed, and their costs, do not appear to be less in patients following coronary revascularisation procedures.

We acknowledge that pharmaceutical costs do not comprise the full cost of medical therapy, and that consultations with health professionals is also an ongoing cost in all groups. However, estimating other resource use attributable to a particular condition, such as general practitioner consultations, is difficult because the reasons for consultations are not included in administrative data, and people may see their general practitioner for a variety of reasons. We did not attempt to estimate other such costs because of this uncertainty, and the aim of this study was to compare the burden of pharmaceutical use and costs across the three groups, which is useful information in itself.

With regard to duration of DAPT, prescription for longer than 12 months may have been influenced by recurrent ischaemic events, or a perceived high risk of recurrent event. However, it seems unlikely that almost $80 \%$ of patients would be stratified at high risk of an ischaemic event, or experienced a repeat event within 12 months of commencement of DAPT.

Related to this, we found the main driver of the differences in costs between the groups to be antiplatelet therapy, primarily clopidogrel. Our analysis showed a greater proportion of people in the medical therapy group had DAPT for longer. It is difficult to know what effect a longer term analysis might have, but it is possible that the duration of dual antiplatelet may also affect mean total costs, over a longer term. It is not clear whether this would affect one group more than the other, nor how this might affect mean cost estimates.

We also acknowledge that because the MBS data relate to services and care provided in a private setting, we are not able to identify admissions to public hospitals. While repeat coronary disease-related hospitalisations or procedures in public hospitals may account for extended durations of DAPT in some patients in either the stent or medical therapy groups, this is unlikely to account for the magnitude and frequency of DAPT prescribed beyond the expected 12-month period in patients who are privately insured.

We also acknowledge that while we attempted to exclude patients, from both groups, who were taking a non-aspirin antiplatelet due to aspirin intolerance, it is possible that some patients continued their non-aspirin antiplatelet and discontinued taking aspirin after 12 months, meaning they were only receiving monotherapy after that time. Again, we do not expect this limitation to affect many patients.

\section{Summary}

One of the main reasons for carrying out percutaneous coronary intervention with stent insertion is that it should reduce the number of drugs patients are required to take. However, based on our analysis of PBS data across the three patient groups, percutaneous coronary intervention did not affect the costs or use of drugs used for relief of angina. It is not clear whether this occurs due to poor reassessment of prescriptions or because symptoms persist following intervention, and this warrants further investigation.

Similarly, on the basis of our findings, Australian patients who receive DAPT treatment may frequently be continued for longer than recommended by the guidelines. This may put some patients at an unnecessarily elevated risk of bleeding, with a negligible effect on ischaemic outcomes, ${ }^{23}$ and be a waste of resources.

Other research in Australia has found underutilisation of DAPT following acute coronary events, defined by a prescription on hospital discharge, and estimates that only $70 \%$ of patients admitted for acute coronary syndrome were discharged with DAPT. ${ }^{21}$ Together with our work, this suggests problems with both initiation and cessation of DAPT in Australia.

Investigation into the reasons for extended dual antiplatelet prescription is needed, particularly given the additional risk of bleeding associated with long-term use of these drugs. An assessment of the impact of reduced duration of DAPT on the costs and risks associated with treating patients with coronary artery disease would also be of interest to policy-makers and healthcare funders. A study to that effect has been proposed in Canada. ${ }^{22}$

Contributors VM and WAP contributed to study design, analysis methods and revisions of the manuscript. VM performed the analyses and prepared the first draft of the manuscript. NG and AGB contributed to analysis methods and revisions of the manuscript. DCW and CO developed the QSkin study, were responsible for the data collection and cleaning and reviewed the manuscript. All the authors gave their approval for the final version of the manuscript. All the authors agree to be accountable for all aspects of the manuscript.

Funding The QSkin Study is supported by a programme grant (APP1073898) from the National Health and Medical Research Council of Australia (NHMRC). DCW is supported by a research fellowship from the NHMRC. VM receives PhD Scholarship funding from the Capital Markets Cooperative Research Centre.

Competing interests None declared.

Patient consent for publication Not applicable.

Ethics approval The Human Research Ethics Committee at the QIMR Berghofer Medical Research Institute approved the QSkin study (project number: P1309). These analyses used non-identified data only, and thus the current study was exempt from ethical review by the QUT Human Research Ethics Committee (exemption number 1600000095).

Provenance and peer review Not commissioned; externally peer reviewed.

Data availability statement Data are available upon reasonable request.

Open access This is an open access article distributed in accordance with the Creative Commons Attribution Non Commercial (CC BY-NC 4.0) license, which permits others to distribute, remix, adapt, build upon this work non-commercially, and license their derivative works on different terms, provided the original work is properly cited, appropriate credit is given, any changes made indicated, and the use is non-commercial. See: http://creativecommons.org/licenses/by-nc/4.0/.

ORCID iDs 
Victoria McCreanor http://orcid.org/0000-0002-0589-8521

William A Parsonage http://orcid.org/0000-0002-0223-5378

Catherine Olsen http://orcid.org/0000-0003-4483-1888

Adrian G Barnett http://orcid.org/0000-0001-6339-0374

Nicholas Graves http://orcid.org/0000-0002-5559-3267

\section{REFERENCES}

1. Stone GW, Hochman JS, Williams DO, et al. Medical therapy with versus without revascularization in stable patients with moderate and severe ischemia: the case for community equipoise. J Am Coll Cardiol 2016;67:81-99.

2. Levine GN, Bates ER, Bittl JA, et al. 2016 ACC/AHA guideline focused update on duration of dual antiplatelet therapy in patients with coronary artery disease. J Am Coll Cardiol 2016;68:1082-115.

3. Valgimigli M, Bueno H, Byrne RA, et al. 2017 ESC focused update on dual antiplatelet therapy in coronary artery disease developed in collaboration with EACTS: the task force for dual antiplatelet therapy in coronary artery disease of the European Society of Cardiology (ESC) and of the European association for Cardio-Thoracic Surgery (EACTS). Eur Heart J 2018;39:213-60.

4. Gargiulo G, Windecker S, da Costa BR, et al. Short term versus long term dual antiplatelet therapy after implantation of drug eluting stent in patients with or without diabetes: systematic review and metaanalysis of individual participant data from randomised trials. BMJ 2016;355.

5. Valgimigli M, Campo G, Monti M, et al. Short- versus long-term duration of dual-antiplatelet therapy after coronary stenting: a randomized multicenter trial. Circulation 2012:125:2015-26.

6. Montalescot G, Brieger D, Dalby AJ, et al. Duration of dual antiplatelet therapy after coronary stenting: a review of the evidence. J Am Coll Cardiol 2015;66:832-47.

7. Olsen CM, Green AC, Neale RE, et al. Cohort profile: the QSkin sun and health study. Int J Epidemiol 2012;41:929-29i.

8. WHO Collaborating Centre of Drug Statistics Methodology. ATC/ DDD Index 2018 Olso: Norwegian Institute of Public Health, 2017. Available: https://www.whocc.no/atc_ddd_index/ [Accessed 13 Aug 2018].

9. World Health Organization. Essential medicines and health products: ATC/DDD Toolkit: World Health Organization. Available: http://www. who.int/medicines/regulation/medicines-safety/toolkit/en/ [Accessed 13 Aug 2018].

10. Australian Government, Department of Health. PBS Downloads Canberra: Commonwealth of Australia, 2018. Available: http://www. pbs.gov.au/browse/downloads [Accessed 21 Jan 2019].
11. Australian Prudential Regulation Authority. Private health insurance Quarterly statistics 2019.

12. Australian Bureau of Statistics. Private health insurance: a snapshot, 2004-05 Canberra, 2006. Available: https://www.abs.gov.au/ AUSSTATS/abs@.nsf/Lookup/4815.0.55.001Main+Features1200405?OpenDocument [Accessed 24 May 2019].

13. Australian Bureau of Statistics. Consumer price index, Australia, Dec 2017 Canberra: Commonwealth of Australia, 2017. Available: http:// www.abs.gov.au/AUSSTATS/abs@.nsf/DetailsPage/6401.0Dec\% 202017? OpenDocument [Accessed 22 Feb 2018].

14. Chew DP, Aroney CN, Aylward PE, et al. 2011 addendum to the National Heart Foundation of Australia/Cardiac Society of Australia and New Zealand guidelines for the management of acute coronary syndromes (ACS) 2006. Heart Lung Circ 2011;20:487-502.

15. Aroney CN, Aylward P, Kelly AM, et al. Guidelines for the management of acute coronary syndromes 2006. Med J Aust 2006;184(8 (Suppl)):S1-32.

16. Palmerini $\mathrm{T}$, Benedetto $\mathrm{U}$, Bacchi-Reggiani $\mathrm{L}$, et al. Mortality in patients treated with extended duration dual antiplatelet therapy after drug-eluting stent implantation: a pairwise and Bayesian network meta-analysis of randomised trials. Lancet 2015;385:2371-82.

17. Montalescot G, Sechtem U, Achenbach S, et al. 2013 ESC guidelines on the management of stable coronary artery disease: the task force on the management of stable coronary artery disease of the European Society of Cardiology. Eur Heart J 2013;34:2949-3003.

18. Hamm CW, Bassand J-P, Agewall S, et al. ESC guidelines for the management of acute coronary syndromes in patients presenting without persistent ST-segment elevation: the task force for the management of acute coronary syndromes (ACS) in patients presenting without persistent ST-segment elevation of the European Society of Cardiology (ESC). Eur Heart J 2011;32:2999-3054.

19. Chew DP, Scott IA, Cullen L, et al. National Heart Foundation of Australia \& Cardiac Society of Australia and New Zealand: Australian Clinical Guidelines for the Management of Acute Coronary Syndromes 2016. Heart Lung Circ 2016;25:895-951.

20. Australian Institute of Health and Welfare. Data tables: cardiovascular disease 2018 Canberra, 2018. Available: https://www.aihw.gov.au/ reports-statistics/health-conditions-disability-deaths/heart-strokevascular-diseases/data [Accessed 21 Jan 2019].

21. Anastasius M, Lau JK, Hyun K, et al. The underutilisation of dual antiplatelet therapy in acute coronary syndrome. Int $J$ Cardiol 2017;:240:30-6.

22. Dual Antiplatelet Therapy Following Percutaneous Coronary Intervention: Clinical and Economic Impact of Standard Versus Extended Duration - Project Protocol CADTH Optimal Use Reports. Ottawa (ON): Canadian Agency for Drugs and Technologies in Health, 2018. 